\title{
Biologists deploy database to quash drug-resistant bacteria
}

Tom Clarke

European microbiologists have assembled a database to help combat the rising tide of antibiotic-resistant bacteria.

A multinational effort involving 12 research centres has collected information on the known European strains of methicillinresistant Staphylococcus aureus (MRSA), and has standardized the technique for identifying the bacteria (S. Murchan et al. J. Clin. Microbiol. 41, 1574-1585;2003).

"We've mapped the existing distribution of strains and followed the current spread of others," says Barry Cookson, a microbiologist at London's Central Public Health Laboratory (CPHL) wholed the initiative. The results confirm reports that some strains of MRSA have managed to jump between hospitals, both within Europe and farther afield.

Although normal strains of $S$. aureus are common and relatively harmless, MRSA has become a significant problem in hospitals, where it tends to prosper because of the pervasive use of antibiotics. The bacteria can infect the lungs, bones and bloodstream of patients, and are responsible for thousands of deaths worldwide each year.

In the past year, MRSA strains have also begun to appear that are resistant to vancomycin, the antibiotic used by most hospitals as their last resort, as well as to the completely new antibiotic linezolid. In addition, outbreaks of MRSA infections that are not associated with hospitals are becoming more common.

Many hospitals have experience of treating their native strains of MRSA using cocktails of various antibiotics. But the database should allow them to identify any new strain early, which could prevent the invaders from gaining a foothold. "People will be able to identify and communicate what could be a common problem," says Alex van Belkum, a microbiologist at Erasmus University Medical Center in Rotterdam, the Netherlands, one of the paper's authors.

The identification method recommended by the European team is pulsed-field gel electrophoresis (PFGE). This identifies strains based on how far fragments of their DNA move through a gel under the influence of electrical pulses. But minute variations in the gel's preparation and the electric field can give variable readings, the researchers say.

PFGE is so sensitive that results can vary "depending on whether its raining or not", jokes microbiologist Tyrone Pitt at the CPHL. To overcome this, the team has specified the amount of gel to be used, the concentration of DNA in the sample, the temperature, and the timing of the electrical pulses.

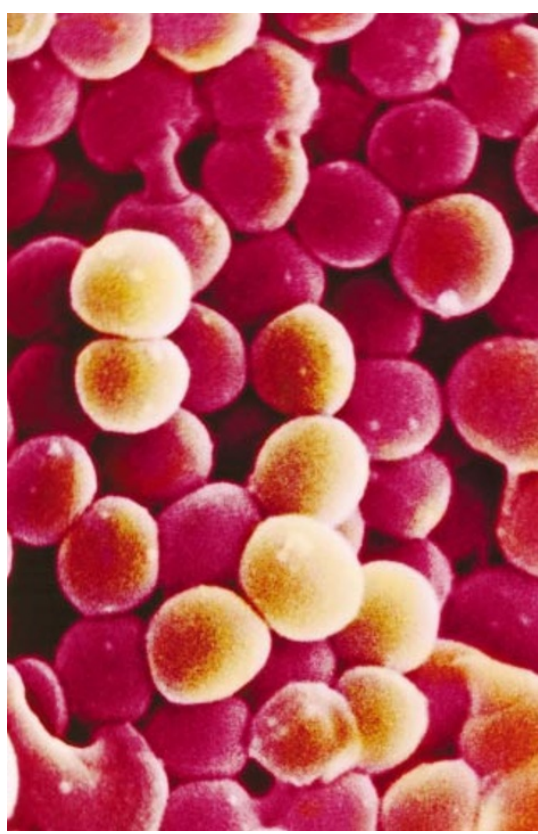

Caught: drug-resistant strains of Staphylococcus aureus can now be identified more readily.

Gel images from any lab can now be matched with strains held on the database and reliably identified, the researchers say.

The European team is now pushing to get the standard PFGE protocols adopted by the International Union of Microbiological Societies. Global standardization and a central database could be valuable in preventing the spread of the bacteria. Already MRSA strains first isolated in Europe have reached Australia and New Zealand, where hospitals have begun screening doctors visiting from parts of Europe for MRSA in case they have brought the bacteria with them.

The US Centers for Disease Control and Prevention (CDC) in Atlanta, Georgia, is also assembling an MRSA database. "We'll have it up and running by the end of the year," says CDC microbiologist Fred Tenover. Initial work between the CDC and researchers in the Netherlands suggests that the two PFGE protocols will be roughly comparable. "It's a bit ad hoc but we are certainly able to share information," says Tenover.

Both the European consortium and the CDC are also developing PFGE protocols for antibiotic-resistant Pseudomonas aeruginosa and Enterococcus bacteria.

In the long term, PFGE tests are likely to be replaced by definitive genome-sequence data for each strain of bacteria. But for now, most hospitals and public-health labs lack the means to produce such sequence data for strains that they want to check.
National Academies launch grants for interdisciplinary work

\section{Erika Check, Washington}

The US National Academies are set to start awarding grants of their own for the first time, under a \$40-million project funded by the California-based W. M. Keck Foundation.

The National Academies Keck Futures Initiative will focus on interdisciplinary research, says Ken Fulton, who will head it. As part of the initiative, the academies will host small meetings to bring together researchers from various disciplines to discuss particular themes.

Researchers who attend the meetings may subsequently apply for grants worth $\$ 200,000$ to support interdisciplinary projects. The programme is funded for 15 years, and four seed grants are expected to be given during its first four years.

"We're hoping to foster innovative, imaginative cross-disciplinary work that might not have occurred without the interaction of the investigators at these conferences," Fulton says.

Conferences will be held twice a year, beginning this November with a meeting on signalling in neuroscience, cell biology and engineering. Participants will be asked to discuss how signalling networks convey information in physical and biological systems, and how these systems can inform each other. Future topics will include nanotechnology and genomics.

Although the money will only support a few researchers, a spokeswoman for the Keck Foundation says that the initiative hopes to reach a broader audience through the conferences. The project is also intended to affect the research direction of funding agencies such as the National Science Foundation and the National Institutes of Health, which have often been criticized as slow to support multidisciplinary work. Representatives from these government agencies will be invited to the meetings, she adds.

"We're trying to get scientists from across disciplines to sit down and ask new questions, rather than having the biologists ask the mathematicians to help them solve a piece of the problem in some research they're conducting," says a spokesman for the Keck Foundation. The futures initiative will fund a National Academies consensus study on how best to foster interdisciplinary research.

The academies will also rename their new building in Washington DC, which opened last year. On 13 May, the building will be christened the Keck Center of the National Academies. 